\title{
MANAGEMENT OF LIVER ABSCESS: AN INSTITUTIONAL EXPERIENCE
}

\author{
Ershad Hussain Galeti1 ${ }^{1}$ Yugavardhan N², Gousia Begum Sowdagar ${ }^{3}$ \\ ${ }^{1}$ Assistant Professor, Department of General Surgery, PES Medical College, Kuppam. \\ 2Postgraduate, Department of General Surgery, PES Medical College, Kuppam. \\ 3Postgraduate, Department of Anaesthesia, PES Medical College, Kuppam.
}

ABSTRACT
BACKGROUND
The aim of this study was to compare the effectiveness of conservative medical treatment versus minimal invasive surgical
techniques like Percutaneous Catheter Drainage (PCD), Percutaneous Needle Aspiration (PNA) and Laparoscopic Washout and
Drainage (LWD) in the management of liver abscess.

\section{MATERIALS AND METHODS}

All patients with liver abscess who were admitted in Surgery from September 2014 to August 2016 were included in this study and were exposed to four different treatment modalities. The patients were first treated with combination of medicine. If they failed to respond to this treatment, they were subjected to ultrasound-guided aspiration. If it failed they were exposed to pigtail catheter placement. Final option was laparoscopic washout and drainage if it was ruptured liver abscess and if the patient presented with septicaemia and peritonitis. PNA was repeated every third day and if the cavity had not declined to $50 \%$ of the original for upto three times then it was considered failure of treatment and PCD was done.

\section{RESULTS}

Out of 54 patients 15 patients responded to drug therapy alone, 36 patients required ultrasound-guided aspiration and pigtail catheter placement and 3 patients required laparoscopic washout and drainage. A combination of drug therapy and ultrasoundguided needle aspiration/pigtail catheter placement was effective for majority of $85 \%$ patients.

\section{CONCLUSION}

Minimal surgical interventions like PNA and PCD are better than conservative treatment for the management of liver abscesses of size $>5 \mathrm{~cm}$, in terms of duration to attain clinical relief and duration of which parenteral antibiotics are needed. Pyogenic liver abscess are more common than amoebic liver abscess. Right lobe of liver is most commonly involved in both type of abscesses. Radioimaging techniques like Ultrasonography (US) and Computerised Tomography (CT) are the modalities of choice for investigation purposes. Treatment modalities of these abscesses first emphasises on medical treatment, but if it is unsuccessful then only the surgical intervention should be taken up. Laparoscopic washout and drainage remains the standard of care for ruptured liver abscess.

\section{KEYWORDS}

Pyogenic Liver Abscess, Amoebic Liver Abscess, Percutaneous Needle Aspiration (PNA), Percutaneous Catheter Drainage (PCD).

HOW TO CITE THIS ARTICLE: Galeti EH, Yugavardhan N, Sowdagar GB. Management of liver abscess: an institutional experience. J. Evolution Med. Dent. Sci. 2016;5(79):5863-5866, DOI: 10.14260/jemds/2016/1322

\section{BACKGROUND}

Liver is an important and vital organ of the body. This organ is subjected to numerous systemic infections viral, bacterial and parasitic and lies at the distal end of the portal circulation; it is therefore bathed with portal blood containing viruses, bacteria parasites, ova, products of digestion and other antigens. ${ }^{1}$ Amoebic Liver Abscess (ALA) and Pyogenic Liver Abscess (PLA) are common clinical problems in India and other tropical countries Pyogenic liver abscess can be single or multiple. The right lobe is more than two times affected as compared to left, while in $5 \%$ cases both lobes of liver are involved. Amoebic liver abscess occurs in population where Entamoeba histolytica is endemic and it affects right lobe in

Financial or Other, Competing Interest: None.

Submission 12-09-2016, Peer Review 23-09-2016,

Acceptance 26-09-2016, Published 30-09-2016.

Corresponding Author:

Dr. Ershad Hussain Galeti,

Noble Hospital, LBS Road,

Pileru-517214.

E-mail:dr.ershadhussain@gmail.com

DOI: $10.14260 /$ jemds $/ 2016 / 1322$
$80 \%$ of cases. Hepatic abscesses develop insidiously with fever, sweats, weight loss and no local signs other than painless or slightly tender hepatomegaly. In patients it presents with abrupt onset of fever, nausea, vomiting, severe abdominal pain with or without jaundice and polymorphonucleosis. Computed Tomography (CT) and ultrasound are the imaging studies of choice. ${ }^{2}$ Currently, these patients are treated with antibiotics along with Percutaneous Needle Aspiration (PNA) or Percutaneous Catheter Drainage (PCD), surgical drainage being used only in patients who fail to respond to such treatment. 3,4

\section{AIMS AND OBJECTIVES}

- $\quad$ To study the clinic-aetiological, demographic profile and management of liver abscess.

- To evaluate the outcome associated with different treatment strategies of liver abscess.

\section{MATERIALS AND METHODS}

This study was conducted prospectively over a period of 2 years from September 2014 to August 2016 in the Department of General Surgery at PES Medical College, a tertiary level teaching hospital. Patient data was collected from all patients 
attending general surgery Outdoor Patient Department (OPD), casualty and inpatient departments in patients with pyogenic and amoebic liver abscess. Detailed history of patients was entered in a proforma. Complete haemogram, renal function test, Liver Function Test (LFT), prothrombin time, clotting time, bleeding time, serum electrolytes, serum amylase and viral markers (HIV, HBsAg) were done. Preliminary ultrasound of abdomen was done on the same day of presentation. Erect X-ray abdomen and CECT whole abdomen (Optional) were also done. Patients were treated according to respective protocol. Patients on conservative line were followed up daily clinically. LFT and USG Abdomen were repeated on the $3^{\text {rd }}$ day, if patients were not relieved symptomatically. Patient was informed about any surgical procedure and consent was taken for the same.

\section{Management Strategies were as Follows}

- Antibiotics alone in abscess measuring $2 \mathrm{~cm}-5 \mathrm{~cm}$.

- Percutaneous aspiration + antibiotics in abscess measuring $>5 \mathrm{~cm}$.

- Percutaneous catheter drainage + antibiotics in abscess measuring $5 \mathrm{~cm}-10 \mathrm{~cm}$ and catheter was removed 24 hours after drain was less than $10 \mathrm{~mL}$ and after ultrasound abdomen confirmation.

- Laparoscopic washout and drainage + antibiotics in ruptured liver abscess was done.

\section{Inclusion Criteria}

- All cases of liver abscess diagnosed clinically and ultrasonographically.

- All cases of diagnosed liver abscess being referred to our hospital.

- $\quad$ All adult patients ( $>18$ years of age).

\section{Exclusion Criteria}

- Immunocompromised patients.

- Patients under 18 years of age.

- Patients with associated malignancy.

\section{RESULTS}

During the study period, 54 patients were admitted with liver abscess. Age of our patients ranged from 18 to 65 years. Males outnumbered females in the ratio $48: 6$ as per Table $1 ; 36$ patients were diagnosed to have pyogenic liver abscess and 18 patients had amoebic liver abscess based on serological tests.

Total 49 patients presented with upper abdominal pain, high-grade fever was present in 40 patients, nausea and vomiting in 25 patients and loss of appetite in 27 patients as per Table 2.

Alcohol addiction was common in males and had an important correlation with liver abscess as per Table 3 .

Majority of liver abscesses were found in right lobe of liver $(85 \%)$ and $5 \%$ of liver abscess was found in left lobe and both lobes were involved in $10 \%$ of patients as per Table $4 ; 72 \%$ of liver abscess was solitary in presentation, multiple abscesses were found in $28 \%$ cases. Majority (75\%) cases were liquefied liver abscess and $25 \%$ cases were predominantly solidified. The laboratory investigations revealed that $45 \%$ patients had haemoglobin levels $<10 \mathrm{gm} \%, 80 \%$ patients had high leucocyte counts and $20 \%$ had hyperbilirubinaemia. The microbiological reports revealed $45 \%$ cases were positive for E. coli, $32 \%$ were positive for Klebsiella, $10 \%$ positive for staphylococcus, $8 \%$ were positive for Bacteroides as per Table 5.
Intravenous antibiotics in form of cephalosporins of fluoroquinolones and metronidazole were given to all patients. About 15 patients were treated successful by this conservative management, 36 patients required minimal surgical interventions like PNA and PCD and 3 patients required Laparoscopic washout and drainage as per Table 6 .

Mean abscess size in the aspiration group was $6.9 \mathrm{~cm}$ and that in PCD was $11.7 \mathrm{~cm}$ as per Table 7. Rupture of abscess into peritoneal cavity was the major complication occurred in 3 cases.

\begin{tabular}{|c|c|c|c|c|c|}
\hline $\begin{array}{c}\text { Age } \\
\text { (In Years) }\end{array}$ & $\mathbf{1 8 - 2 5}$ & $\mathbf{2 5 - 3 5}$ & $\mathbf{3 5 - 4 5}$ & $\mathbf{4 5 - 5 5}$ & $\mathbf{5 5 - 6 5}$ \\
\hline No. of Patients & 4 & 12 & 26 & 8 & 4 \\
\hline \multicolumn{6}{|c|}{ Table 1: Age Wise Distribution in Years } \\
\hline
\end{tabular}

\begin{tabular}{|c|c|c|c|c|c|}
\hline Symptoms & Pain & Fever & $\begin{array}{c}\text { Nausea \& } \\
\text { Vomiting }\end{array}$ & Anorexia & Jaundice \\
\hline $\begin{array}{c}\text { No. of } \\
\text { Patients }\end{array}$ & 49 & 40 & 25 & 27 & 12 \\
\hline \multicolumn{5}{|c|}{ Table 2: Symptomatology } \\
\hline
\end{tabular}

\begin{tabular}{|c|c|c|}
\hline & Total $(\mathbf{n}=\mathbf{5 4})$ & $\mathbf{\%}$ \\
\hline Males & 48 & 88 \\
\hline Duration $<10$ years & 20 & 42 \\
\hline Duration $>10$ years & 28 & 48 \\
\hline
\end{tabular}

Table 3: Alcoholism in Case of Liver Abscess

\begin{tabular}{|c|c|c|c|}
\hline Lobe Affected & Right Lobe & Left Lobe & Both Lobes \\
\hline Percentage & 85 & 5 & 10 \\
\hline \multicolumn{3}{|c|}{ Table 4: Anatomical Location } \\
\hline
\end{tabular}

\begin{tabular}{|c|c|c|c|c|}
\hline Organism & $\begin{array}{c}\text { E. } \\
\text { Coli }\end{array}$ & Klebsiella & Staphylococcus & Bacteroides \\
\hline Percentage & 45 & 32 & 10 & 8 \\
\hline \multicolumn{4}{|c|}{ Table 5: Microbiology } \\
\hline
\end{tabular}

\begin{tabular}{|c|c|c|c|}
\hline Treatment & $\begin{array}{c}\text { Antibiotics } \\
\text { Alone }\end{array}$ & $\begin{array}{c}\text { PNA and } \\
\text { PCD }\end{array}$ & $\begin{array}{c}\text { Laparoscopic } \\
\text { Drainage }\end{array}$ \\
\hline No. of Patients & 15 & 36 & 3 \\
\hline \multicolumn{3}{|c|}{ Table 6: Modalities of Treatment } \\
\hline
\end{tabular}

\begin{tabular}{|c|c|}
\hline Size in CM & Treatment Modality \\
\hline$<5 \mathrm{~cm}$ & Antibiotics Alone \\
\hline $5 \mathrm{~cm}-10 \mathrm{~cm}$ & Antibiotics + PNA \\
\hline$>10 \mathrm{~cm}$ & Antibiotics + PCD \\
\hline Ruptured Abscess & Laparoscopic Drainage \\
\hline \multicolumn{2}{|c|}{ Table 7: Size of Abscess and Treatment Modality } \\
\hline
\end{tabular}

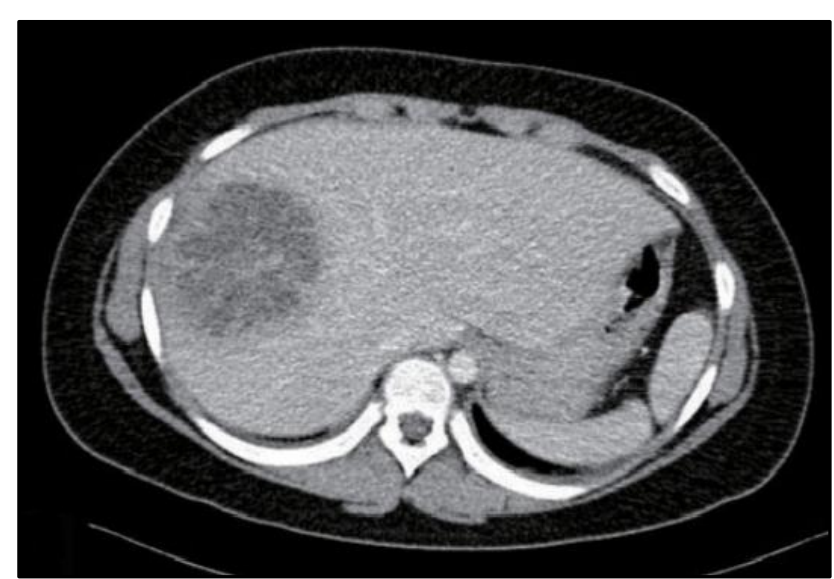

Fig. 1: CT Scan showing Abscess in the Right Lobe of the Liver for which Percutaneous Aspiration was Done 


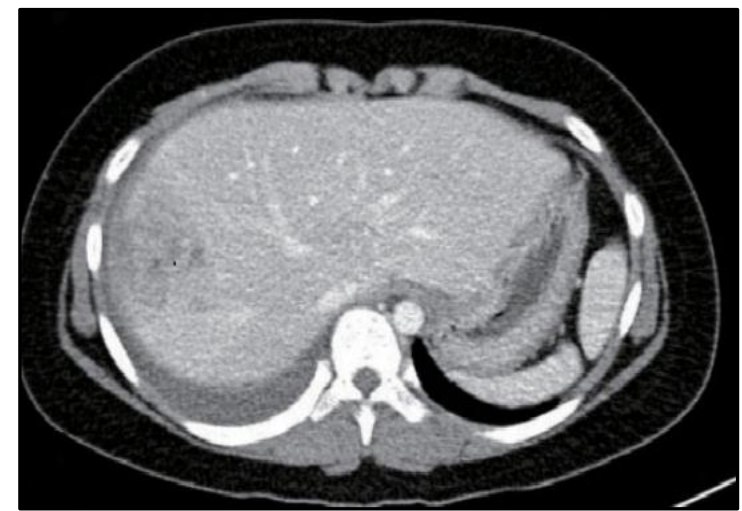

Fig. 2: Post Aspiration and Antibiotics, Size of the Abscess Reduced and Complaints of the Patient Relieved

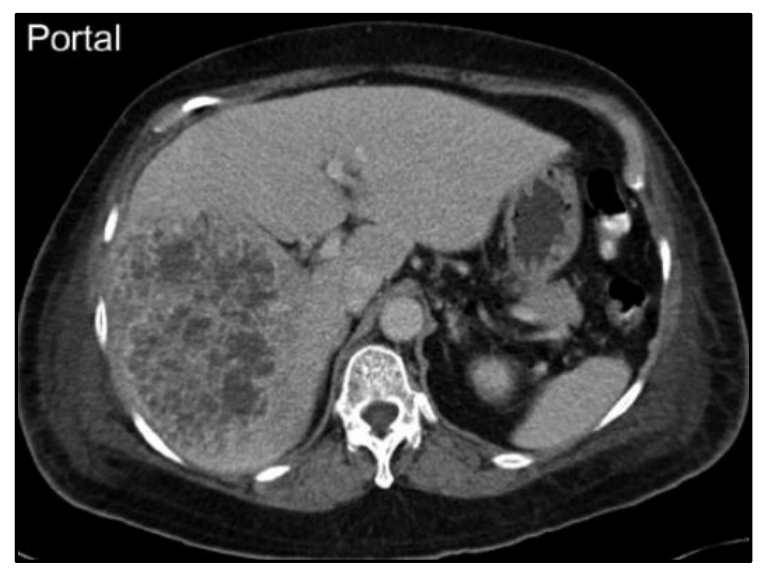

Fig. 3: Klebsiella Liver Abscess in the Right Lobe of the Liver

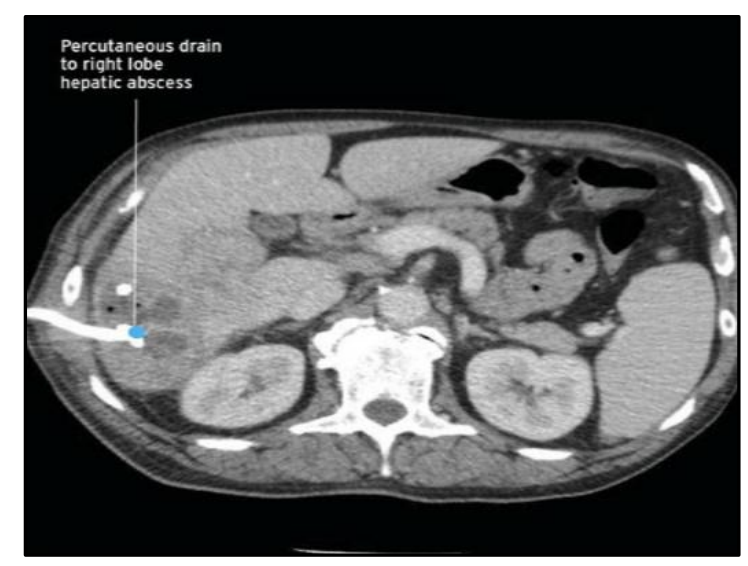

CT showing Right Hepatic Lobe Liver Abscess with Percutaneous Drainage

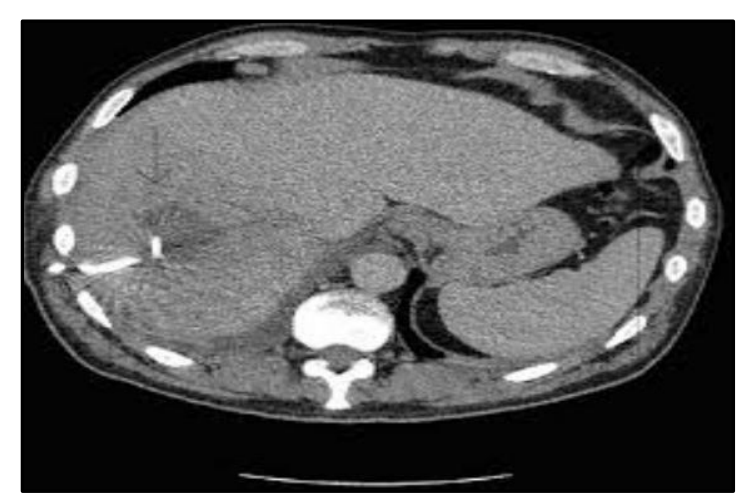

CT Scan showing Reduction in the Size of the Abscess following Drain Placement

\section{DISCUSSION}

Liver abscesses are life-threatening with mortality rate as high as 80 to $90 \%$ if left untreated. ${ }^{5}$ In earlier times when antibiotics were not available, open surgical drainage was the treatment of choice. Treatment by aspiration and percutaneous drainage followed by antibiotics has largely replaced surgical drainage.

\section{Pyogenic Liver Abscess}

In half of the cases, no identifiable cause of pyogenic liver abscess was ascertained. With ultrasound initially the abscess is hyperechoic, but later with maturation it becomes hypoechoic. Computer tomography is more specific and sensitive than ultrasound. E. coli and Klebsiella being the commonest causative organism. The choice of antibiotic should cover most of the common microorganisms cultured from liver abscess. This therapy should consist of a combination of aminoglycosides either with metronidazole or beta-lactam antibiotic. Antibiotic alone should be reserved in patients with solitary abscess less than $5 \mathrm{~cm}$ for patients in good clinical condition. Patients must receive antibiotic for 46 weeks.

Percutaneous procedure are performed under USG or CT guidance. Aspiration of pyogenic liver abscess to confirm the diagnosis and obtain pus for culture should be accompanied by complete aspiration of the pus or insertion of a drain at the same time. PNA has a high success rate and a shorter hospital stay, but a large percentage requires second or third aspirations to achieve success. ${ }^{6}$ When PNA fails, catheter drainage should be performed. PCD is performed when pus is too thick to be aspirated, the wall is thick and non-collapsible when the abscess is multiloculated.

The indication of primary surgical intervention (Laparoscopic drainage) is in patients with intraperitoneal rupture presenting with peritonitis and septicaemia. ${ }^{7}$

\section{Amoebic Liver Abscess (ALA)}

It is the most common extraintestinal site of infection, but occurs in only less than $1 \%$ of E. histolytica infections. ${ }^{8}$ ALAs are 3 to 10 times more common in men. ${ }^{9}$

ALA lesions are usually single and mostly found in the right lobe of the liver. The incidence of ALA of the left lobe ranges from $5 \%$ to $21 \%$. The liver abscess has a thin capsular wall with a necrotic centre composed of a thick fluid. Typically, abscess fluid is odourless resembling 'chocolate syrup or anchovy paste' in half and bacteriologically sterile, although secondary bacterial invasion may occur (in 15 to 20\%). The mortality rate has been estimated to be around $0.2-2.0 \%$ in adults and up to $26 \%$ in children. Approximately $20 \%$ have a past history of dysentery and another 10\% history of diarrhoea or dysentery at the time of diagnosis. 10

Indirect Haemagglutinin Assays (IHA) is the most sensitive test $(90 \%)$. Antibody may be negative in early infection and should be repeated 7 days later. IHA may remain positive for up to 20 yrs. and represent a previous infection. ${ }^{11}$ EIA (Enzyme-Linked Immunosorbent Assays) is the most commonly employed test and it usually become negative within 6-12 months. ${ }^{12}$ A negative serology, however, does not exclude the diagnosis.

USG findings are good for radiological evaluation of amoebic liver abscess, which shows peripheral rim with homogeneity. The first line of treatment in ALA is 
metronidazole. The size of abscesses is important factor in determining the response of drug.

PCD and PNA offer other modalities of treatment as in pyogenic abscesses. Metronidazole is given $750 \mathrm{mg} 3$ times a day for 7-10 days.

Routine aspiration of liver abscess is not indicated for diagnostic or therapeutic purposes. ${ }^{13} \mathrm{~A}$ combination of USG findings with a positive serology in the appropriate clinical setting is adequate to start drug therapy. Aspiration has been indicated when there is lack of improvement in 48-72 hours, left lobe abscess, large abscess having impending rupture, compression sign, thin rim of liver tissue around the abscess $(<10 \mathrm{~mm}) \cdot{ }^{14}$

Surgical open or laparoscopic drainage is indicated only in those patients with complicated amoebic abscesses like secondary infection or peritonitis.

\section{CONCLUSION}

Liver abscess is a very common condition in India. India has 2nd highest incidence of liver abscess in world. Liver abscesses occurred most commonly between 30-60 years. Most of the cases had an acute presentation and the right lobe is commonly affected. Pain in the abdomen was the most common symptom present in most cases. Alcohol consumption was the single most important aetiological factor for causation of liver abscesses. Alkaline phosphatase is the most consistently elevated among all liver functions. Raised WBC count, Alkaline phosphatase level, Diabetes, Hypoalbuminaemia, Prolonged Prothrombin time were considered as the predictive factors of complicated liver abscess in this study. Percutaneous needle aspiration and percutaneous catheter drainage are more effective than conservative medical management in treatment of liver abscess; however, size of liver abscess also influence the outcome. Laparoscopic approach is a useful tool in cases of ruptured liver abscesses.

\section{REFERENCES}

1. Branum GD, Tyson GS, Branum MA, et al. Hepatic abscess. Changes in etiology, diagnosis and management. Ann Surg 1990;212(6):655-62.

2. Saini S. Imaging of the hepatobiliary tract. N Engl J Med 1997;336(26):1889-94.

3. Krige JE, Beckingham IJ. ABC of diseases of liver, pancreas, and biliary system. BMJ 2001;322(7285):537-40.

4. Wong KP. Percutaneous drainage of pyogenic liver abscesses. World J Surg 1990;14(4):492-7.

5. Chou FF, Sheen-Chen SM, Chen YS, et al. Single and multiple pyogenic liver abscesses: clinical course, etiology and results of treatment. World J Surg 1997;21(4):384-9.

6. Yu SC, Ho SS, Lau WY, et al. Treatment of pyogenic liver abscess: prospective randomized comparison of catheter drainage and needle aspiration. Hepatology 2004;39 (4):932-8.

7. Stain SC, Yellin AE, Donovan AJ, et al. Pyogenic liver abscess: modern treatment. Arch Surg 1991;126(8): 991-6.

8. Peters RS, Gitlin N, Libke RD, et al. Amoebic liver diseases. Ann Rev Med 1982;32:161-74.

9. Maltz G, Knauer CM. Amebic liver abscess: a 15-year experience. Am J Gastroenterol 1991;86(6):704-10.

10. Hoffner RJ, Kilaghbian T, Esekogwu VI, et al. Common presentations of amebic liver abscess. Ann Emerg Med 1999;34(4):351-5.

11. Ravdin JI. Amebiasis. Clin Infect Dis 1995;20(6):1453-64.

12. Sharma M, Saxena A, Ghosh S, et al. A simple and rapid Dot-ELISA dipstick technique for detection of antibodies to Entamoeba histolyica in amoebic liver abscess. Indian J Med Res 1988;88:409-15.

13. Stanley SL. Amoebiasis. Lancet 2003;361(9362):1025-34.

14. Ralls PW, Colletti PM, Quinn MF, et al. Sonographic findings in hepatic amoebic abscess. Radiology 1982;145(1):123-6. 